through red media and then printing positives from such, and finally obtaining red, green, and blue prints and supcrimposing them, is not a step in a scientific direction, since it is utterly impossible to secure monochromatic colours which are pure enough to give the truth of naturc. Such efforts, though they may be commercially valuable, yet are not to be followed with too much zeal by scientific photographers.

We may now axiomise the results we have indicated :--

$x$. That the undeveloped photographic image on a silver compound is formed by the reduction of that compound.

2. That the compound may exist in two (or three) molecular groupings.

3. That the compound can only be sensitive to the rays which it absorbs.

4. That the reduced silver compound may be rendered incapable of development by combining with oxygen.

5. That light of every refrangibility may cause an acceleration of oxidation provided the compound acted on absorbs such light.

6 . That the oxidation of the compound reduced by any particular ray may be as rapid as the reduction, and thus to give a false idea of their limit of sensitiveness fo the spectrum.

7. That the oxidation of the reduced silver compound may account for the phenomenon of photographs in natural colours hitherto produced.

8. That in all probability the action of dyes on silver bromide is a secondary one.

$$
\text { W. DE WIVtieslie ABNey }
$$

\section{GELATIN AS A FOOD-PRESERVER}

$R$ EMOVAL of water and exclusion of air are amongst the most effective conditions for the preservation of animal and vegetable foods. If you coat an egg with collodion you may keep it a year, and yet will find it perfectly sound at the last. Iy dipping a mutton-chop in melted paraffin, putrefaction will be prevented. But in both these examples of preservative processes, dependent upon the exclusion of air, you make use of materials which are costly and uneatable. There are analogous drawbacks to all similar plans for preventing injurious changes in articles of food. The tinning method, and the method of simple desiccation in warm dry air, are satisfactory in their results; but the range of alimentary substances amenable to such treatment is not very extensive. In Dr. Campbell Morfit's new "Gelatin Process" we seem to see several points of superiority over most of the older plans for attaining the same end. It is true that chemists have not been in the habit of looking upon gelatin (or indeed any otber similar complex nitrogenous body) as likely to prevent or arrest decay. On the contrary, few solutions afford a more suitable nidus for the development of fungoid germs than a liquid containing gelatin. But the experience of a good many montlis tends to show that food-preparations containing gelatin, if once dried so as not to contain more than 10 or 12 per cent. of moisture, do not become mouldy even when exposed to warm and moist air. A large number of Dr. Morfit's experimental mixtures have been so exposed for some weeks, lying on my office table: yet they have not suffered any decided deterioration. They comprise many perishable foods, such as cabbage, tomato, milk, and meat. Though not of equal merit as specimens of the gelatin process, all are ediblc, and some positively palatable. Further experiment will doubtless enable the inventor to improve his process by modifying it still further, so as to suit a greater variety of vegetable and animal foods.

Perhaps the best way of explaining the nature of Dr. Morfit's invention will be to take as an illustrative example the case of milk. The mere drying-up of milk has bcen tried with but moderate success- the resulting powder becoming quickiy rancid on exposure to the air. The preserved or condensed milk now in such extensive use is in many respects a satisfactory and convenient preparation, but it is mawkishly sweet, containing more than onefourth its weight of added cane sugar. Morcover, in consequence of this addition, the proportion of nitrogenous or flesh-forming substances in it bas been seriously lowered. Now the substitution of gelatin for cane sugar in preserving milk meets both these objections to ordinary condensed milk. The milk preserves its natural and moderate degree of sweetness, while the gelatin, even if its own value as a nitrogenous nutrient be not considered, certainly does not lower the proportion of flesh-formers to heat-givers in the product.

In order to apply his process to the preservation , of milk, Dr. Morfit directs us to dissolve I lb. of gelatin in I gallon of milk at a temperature of $130^{\circ}$ to $140^{\circ} \mathrm{Fahr}$., and then to allow the solution to set into a jelly; this is then cut into slices and dried. By employing the product of this first operation in lieu of fresh gelatin, for gelatinising a second gallon of milk, a jelly is obtained in which the milk-solids are just doubled in amount. As a gallon of milk contains about 6,400 grains of these solid nutrients, casein, milk-sugar, milk-fat, and phosphates, their ratio to the gelatin will become as 12,800 to 7,000 after the second operation just described. If then the dried milk-jujube, as we may call it, be again and again employed with successive quantities of milk, a limit is reached, when the $\mathrm{I} \mathrm{lb}$. of gelatin has been incorporated with ten gallons. At this stage the mixture will contain no more than one part of gelatin to ten parts of the nutritive matters of milk-a proportion of added preservative material which contrasts very favourably with the 25 to 28 per cent. of sugar found in ordinary preserved milk. If the $\mathrm{I} \mathrm{lb}$. of gelatin required could be at once dissolved in the whole eight or ten gallons of milk, the process would be simplified and cheapened, but gelatinisation, an essential part of the method, could not then be secured. For it is the gradual drying up of the slabs of jelly, with which the animal and vegetable food-materials have been uniformly incorporated, that leaves every particle of changeable substance with an adequate protective coating of gelatin.

One at least of Dr. Morfit's preparations has become an article of commerce. He dissolves gelatin in limejuice at a gentle heat, an 1 after removing much of the water and adding sugar, incorporates the mixture with the powder of navy-biscuit. Pressed in moulds and carefully dried, a granular acidulous and agreeable biscuit is produced, which should combine a considerable alimentary value with the anti-scorbutic properties of lime-juice. On analysing the lime-juice jujube, the basis of these biscuits, I find about 8 per cent. of water, 8 of grelatine, 5 of free citric acid, much sugar, and less than I ( $0 \% 7)$ per cent. of mineral matter or ash. This proportion of gelatin is rather high when compared with the free citric acid, the characteristic ingredient of lime-juice; but the sample analysed was made in April, 1877 , and may not represent the exact composition of the recent product. And it becomes a question, whether for travellers' use, it would not be advisable in this preparation to neutralise a little of the acidity of the lime-juice with potash, rather than to mask its presence by an excessive quantity of sugar. Pure lime-juice itself contains very little potash and phosphoric acid or other mineral ris tter; but that fact affords no argument against the introduction of small quantities of these compounds into such a preparation as that now under consideration.

It would be impossible to discuss in detail the applicability of the gclatin process to the preservation and concentration, in an uninjured, compact, and available form, of fruits, of meat, of cheese, \&c., \&c. But it may be safely affirmed that Dr. Morfit's invention has already

been successfully applied in several directions, and that
it is full of promise for the future. it is full of promise for the future. 